\title{
Publisher Correction: Causal peer effects in police misconduct
}

Edika G. Quispe-Torreblanca (D) and Neil Stewart (iD)

Correction to: Nature Human Behaviour https://doi.org/10.1038/s41562-019-0612-8, published online 27 May 2019.

In the version of this article initially published, the sentence beginning "The exclusion restriction required for identification implies..." was missing the letter $\mathrm{H}$. It should have read, "The exclusion restriction required for identification implies that misconduct of the peers of $\mathrm{H}$ in $t-2$ and $t-3$ (that is, misconduct of $\mathrm{I}$, J and $\mathrm{K}$ ) should not affect the current behaviour of T except through their impact on $\mathrm{H}$ in $t-1$." The error has been corrected in the HTML and PDF versions of the article.

Published online: 12 June 2019

https://doi.org/10.1038/s41562-019-0650-2 